\title{
VOLTAR A UMA IMAGEM: IDEIAS ISOLADAS SOBRE DELEUZE-LYNCH E A PEDAGOGIA DA PERCEPÇÃO
}

\section{BACK TO AN IMAGE: ISOLATED IDEAS ABOUT DELEUZE-LYNCH AND THE PEDAGOGY OF PERCEPTION}

Cristiano Bedin da Costa ${ }^{1}$

Elena de Oliveira Schuck ${ }^{2}$

\begin{abstract}
Resumo: O ensaio está dividido em duas partes. A segunda metade é composta pelo texto "Imagem de um segredo: Deleuze-Lynch e a Pedagogia da percepção", apresentado no VIII Seminário Conexões: Deleuze e Corpo e Cena e Máquina e... Nele, toma-se uma cena da série de Twin Peaks como intercessora para pensar relações entre as noções de imagem, segredo e ensino, a partir da obra de Deleuze e Guattari. Na primeira parte, trata-se de pensar o próprio movimento de retorno ao texto original, com as imagens que ele comporta. Escrito em meio ao isolamento social devido ao Covid-19, este movimento, além de redimensionar algumas ideias presentes na apresentação, discute a importância da imagem amorosa em tempos de crise, na medida em que ela pode configurar um espaço de saúde, pensamento e criação.
\end{abstract}

Palavras-chave: Deleuze; imagem; pensamento.

\begin{abstract}
The essay is divided into two parts. The second half consists of the text "Image of a secret: Deleuze-Lynch and the Pedagogy of perception", presented at the VIII Seminário Conexões: Deleuze e Corpo e Cena e Máquina e... In it, a scene from the series of Twin Peaks is taken as an intercessor to think about relations between the notions of image, secret, and teaching, based on the work of Deleuze and Guattari. In the first part, it is a question of thinking about the movement of returning to the original text, with the images it contains. Written amid social isolation due to Covid-19, this movement, in addition to resizing some ideas present in the presentation, discusses the importance of the loving image in times of crisis, as it can configure space for health, thought, and creation.
\end{abstract}

Keywords: Deleuze; image; thought.

\author{
"Ver com olhos livres". \\ Oswald de Andrade, Manifesto da Poesia Pau-Brasil
}

I.

Pode-se sempre voltar para uma imagem. Tê-la como abrigo, habitá-la por amor, claro, mas também por necessidade. Uma imagem como uma barricada, uma imagem como um refrão. Cantá-la. Chamá-la. Invocar e delinear sua presença. Tralalá. Em Paris, Texas, de Win Wenders (1984), o menino Hunter não cansa de requisitar os arquivos em Super-8 da família, um bloco de espaço-tempo que reúne figuras já desaparecidas e no qual ele mal pode se reconhecer, mas que parece garantir a integralidade de sua própria história. Predominância da imagem sobre o sujeito, a vida como uma memória luminosa que se projeta desde "há muito tempo atrás, numa galáxia muito, muito distante...", tal como expressa a alusão cinematográfica feita por ele logo

\footnotetext{
${ }^{1}$ Docente da Faculdade de Educação da Universidade Federal do Rio Grande do Sul (UFRGS), Porto Alegre, RS, Brasil. E-mail: cristianobedindacosta@gmail.com.

${ }^{2}$ Pesquisadora do Centro Brasileiro de Análise e Planejamento (CEBRAP), São Paulo, SP, Brasil. E-mail: elena.schuck@cebrap.org.br.
} 
após um novo retorno, uma outra sessão. "Ciné-filo, cine-filho", diria Serge Daney (2007, p. 235). Um arquivo amoroso e particular de imagens como uma força que antecipa, protege e escreve uma existência singular.

É um movimento sem dúvida semelhante o que fazemos ao revisitar certos retratos de família, buscando encontrar neles a chave para aquilo que somos. Lá, estão paisagens nas quais não estivemos, momentos que não compartilhamos, existências anteriores às nossas, em imagens de um tempo no qual nem sequer éramos contados. No entanto, lá estamos como uma presença potencial, a insistência de um tempo futuro em um isso foi passado: o porvir como resíduo, estranha lógica de desorganização do tempo sequencial (o tempo capaz de ordenar o vivido em termos de passado, presente e futuro). Retroceder, avançar. O jogo amoroso com essas imagens nos faz perceber que a história de uma vida não é uma marcha linear, mas sim uma reflexividade em paralaxe, dentro da qual nossas elaborações do passado tanto dependem quanto definem nossas posições no presente (FOSTER, 2017).

A cada vez, então, ao que voltamos? De lá, o que advém? Voltamos aonde jamais estivemos, ou seja, ao próprio movimento da perda. Cada acontecimento e cada vestígio sondados configuram traços particulares em um arquivo em movimento, retroativamente ativado e recodificado a cada retorno, e que assim pode indicar direções móveis para o futuro. O lugar da perda é precisamente esse instante do qual estamos desde sempre apartados, e em direção ao qual podemos seguir, sem jamais alcançá-lo. Viver é um caso irremediável de aproximações e afastamentos.

Pode-se sempre voltar para certas imagens, traçando assim uma zona operatória dentro da qual o passado é reinscrito, rearranjado, ressignificado. No limite, um modo de estender a temporalidade do próprio presente. Em texto dedicado a Agonia e glória, de Samuel Fuller (1980), Daney (2007, p. 183) estabelece a seguinte distinção entre o cinema e a vida: enquanto no fim de um filme, um pouco de escrita, a palavra FIM, é o que aparece para barrar uma imagem, a história de uma vida não encontra sua imagem final. Ou ao menos não lhe é exigido encontrar. Podemos viver assombrados pelo desejo de terminar, de encontrar o ponto de basta para isso ou aquilo, mas é preciso acreditar que é possível fazer de cada uma das imagens que compõem uma vida um princípio ou mesmo uma zona de passagem, e não uma conclusão. Está aí a verdade da relação entre as palavras, as imagens e a vida. Porque não haveria mais imagens se apenas uma imagem pudesse realmente ir até o fim. Mas basta que nos voltemos às imagens que amamos, basta que tentemos tomá-la entre os dentes, tê-las na ponta da língua, para perceber que elas não se esgotam naquilo que nos permitem dizer. Há sempre algo mais. Há sempre um excesso que não se deixa reduzir, e que por isso institui um espaço para o movimento de ir e vir. Voltar para uma imagem é habitar seus arredores. Não se trata de esgotar sua forma, mas sim de experimentar sua força. Não há outro meio: a imagem, sua verdade, dirá Barthes (2007, p. 211), é precisamente "aquilo de que sou excluído".

Em Takara - A noite em que eu nadei (2017), Damien Manivel e Igarashi Kohei fazem com que o pequeno protagonista desenhe um peixe que irá carregar consigo em seus trajetos à procura do pai. É a imagem da saída de casa, a imagem que se multiplica de modo silencioso, sem palavras, em planos cada vez mais abertos, pelos quais vamos nos distanciando do personagem e nos aproximando da paisagem. Duplo distanciamento, mas também dupla conexão: o menino da casa ao mundo; o espectador do menino àquilo que ele nos possibilita ver. O exterior como totalidade do plano. Takara é o pensamento em ato. O pensamento em seu devir-criança, que inocentemente erra, tateia, explora e se perde no lado de fora. Pensar, nadar, olhar... A imagem como interação e contágio, um pensamento de carne fresca e ossos flexíveis, que se confunde com a paisagem e por isso nela se permite perder. Mais do que qualquer outra coisa, devir-criança é zombar das formas, isto é, usar livremente o mundo. 
Pode-se sempre voltar para uma imagem, mas não estamos certos de que esse retorno se dá por simples vontade do espectador, do ouvinte, do leitor. Os sons, as cores e as linhas, as descrições verbais e as imagens em movimento delimitam espaços precisos, e agenciam movimentos concretos a eles correspondentes. É sob tal perspectiva que nos relacionamos e avaliamos determinadas obras. Tal como indica a lição deleuziana, "uma obra deve fazer jorrar problemas e questões nos quais somos tomados, mais do que dar respostas" (DELEUZE, 2016, p. 305). Trata-se de movimentos, de aberturas e conexões. Não somos os mesmos dentro de um espaço godardiano e outro lynchiano. O cenário da espera em Samuel Beckett não é semelhante ao construído por John Fante. Não se pode habitar com o mesmo corpo os espaços sonoros delineados por Ryuichi Sakamoto, Hodja e Nick Cave. Pedagogia sensório-motora, sem dúvida, mas não só. De um caso a outro, importa considerar a natureza das respostas, a existência ou não de esquematismos através dos quais o que sentimos e o modo como agimos estão ou não estão determinados e pré-estabelecidos. Porque há sempre o risco de nos tornarmos reféns daquilo que amamos, e então não sermos capazes de entregar nada além de automatismos sensoriais e respostas-clichê. "Uma imagem só vale pelos pensamentos que ela cria", disse Deleuze (2016, p. 220) na ocasião da publicação de seu primeiro livro sobre o cinema. Uma lição precisa, e por isso decisiva. O pensamento como medida. Sua possibilidade e força, seu estilo, como termômetros.

É nesse sentido que amar uma imagem diz menos respeito à técnica que a define e ao formato que ela assume do que à força que ela compreende. Ou seja, uma imagem interessa menos por aquilo que ela é e mais por aquilo que ela torna possível ser. É claro que uma ideia cinematográfica desenvolve-se de maneira diferente de uma ideia musical, fotográfica ou literária. No entanto, o valor de uma ideia está naquilo que ela dá a pensar, no modo como ela agencia movimentos concretos de pensamento. No plano amoroso, nenhuma hierarquia entre as artes, portanto. O encontro como medida, o pensamento como fim. "Não se sabe até onde uma verdadeira imagem pode levar...” (DELEUZE, 2018, p. 39).

Pode-se sempre voltar para uma imagem, já que partir e voltar são partes de um só movimento. Uma imagem como um conjunto variado de efeitos, uma imagem como velocidades e lentidões. É o lugar da música em Twin Peaks: O retorno, de David Lynch e Mark Frost (2017), em especial pelo modo como a trama se desenvolve para todos os lados, em linhas cada vez mais velozes e parcialmente independentes, linhas concêntricas, que se separam para traçar outras paisagens, e que então desaceleram e tornam a se cruzar ao final de cada episódio, emaranhadas por um instante, no palco da taberna Roadhouse. A música como a imagem de um bolsão de ar, o espaço sonoro como real condição de continuidade, a garantia de um novo giro.

Em cada caso, a cada retorno, a imagem está implicada com um esforço de "tornar sensíveis, sonoras (ou visíveis) forças ordinariamente imperceptíveis” (DELEUZE, 2018, p. 317). Ou seja: trata-se de ampliar a percepção, do amor como cartografia sensível. Amo, e por isso vejo mais, escuto mais, sinto mais. Não se trata tanto de reagir a uma imagem, no sentido de uma ação motora que viria como resposta a um encontro. Mas sim de sustentar, por amor, uma imagem. Questão de postura: por meio de quais palavras, de quais nuances de cor, de som e de movimento sou capaz de encontrar, para mim, um novo espaço-tempo no qual posso, mesmo que provisoriamente, habitar? Em tal agenciamento, o que há de novo, de ainda não pensado, não experimentado? É nesse sentido que uma imagem não é nunca algo à parte em uma realidade que a envolve, mas sim uma espécie de caixa de ressonância e interferências mútuas.

Em texto recente sobre a experiência de confinamento após ter sido diagnosticado com Covid-19, Paul B. Preciado (2020) conta sobre a escrita de uma carta de amor, que joga no lixo assim que finaliza. A imagem da carta, com o cuidado que envolve tanto o seu preparo quanto o seu descarte, já aparecia nos Fragmentos de um discurso amoroso, de Barthes (2007, p. 17). Em ambos, a evidência de uma conduta íntima que é, antes de qualquer outra coisa, um mínimo 
gesto de resistência frente às demandas impostas pelo mundo. Sendo a única testemunha de seu fazer "para nada", o escritor amoroso não pode encontrar em sua conduta outro sentido que não seja o sentido de sua própria força. Uma carta como um modo de cuidar de si. Nada além disso.

Pode-se sempre voltar para uma imagem. Agora, depois de um vírus mutante ter ultrapassado fronteiras e isolado países; enquanto a ameaça paralisa instituições, esvazia cidades e coloca sob suspensão relações de proximidade, de carne e cheiro, somos a imagem daqueles que dizem e escrevem de casa. Somos aqueles que esperam, porque assim devemos fazer. E porque assim podemos estar. Esperar, dizer, escrever: pelo quê? Para quê? Também o vírus é uma imagem: estranha, incerta, errática, selvagem. Uma reconfiguração dos modos. Um breve instante... E fomos ultrapassados. Há algo mais que nos olha. Há algo mais presente. Há a vida e lá vem a morte. Questão de tempo, questão de espaço. O vírus é a imagem da casa. E a casa, desde que estamos nela, não é um lugar seguro (pedagogia viral: cada um, um lugar suspeito). Sim, o vírus é a imagem da casa, e a casa é um túmulo de nós mesmos. O que será necessário deixar, esquecer, enterrar? Porque é certo que o lugar para onde vamos não comportará os mesmos corpos. Em casa, esperamos o que não éramos, porque o vírus tomou de nós o que somos. Protocolos, curvas, testes: o vírus é uma imagem ubíqua, um arranjo políptico, rápido, mortal. $\mathrm{O}$ vírus é uma imagem esmagadora. Acachapante, claustrofóbica. O vírus é a imagem de um agora órfão de seu passado (um tempo para o qual não deixamos de nos voltar com certa nostalgia) e aparentemente alijado de qualquer futuro minimamente desejável. O desafio é cartográfico.

Como ver mais? Como desviar, perseverar nas imagens que amamos? Como ver além de uma imagem de medo, de solidão, de morte? É Didi-Huberman (2017, p. 61) quem nos lembra que nunca poderemos dizer que não há nada mais para ver, uma vez que para "saber desconfiar do que vemos, devemos saber mais, ver, apesar de tudo". Ora, ver mais é resistir ao embrutecimento das imagem. De certo modo, é interromper a cadeia que faz com que todo olhar esteja vinculado ao mesmo modo de ver, de interpretar, de agir. O elogio feito por Deleuze (1992, p. 90) a uma "pedagogia da percepção" vinculada a certas imagens cinematográficas é também a indicação de um procedimento disponível a cada um de nós, que hoje devemos não apenas viver, mas também educar: o mundo, com todas as coisas que fazem dele um mundo, não é algo que deva ser embelezado ou então descortinado, para que assim se torne possível ver o que está por trás disso ou daquilo. Antes, trata-se de perceber as coisas como planos sem profundidades simuladas e sem saídas. Um livro, uma folha em branco, uma tela, uma cena, uma canção, um quadro em uma sala de aula, um plano de ensino e o próprio vírus que nos assombra são espelhos, superfícies nas quais podemos captar nosso próprio olhar como um olhar a mais: o que vemos? Quem somos nós que olhamos? E desde onde olhamos? É possível continuar olhando? É possível sustentar, de fato, esse olhar? Até onde? Até quando? Sem cortes. O mundo em um único plano.

Voltamos agora àquilo que amávamos e sobre o que falávamos há poucos meses atrás, quando apresentamos no VIII Seminário Conexões: Deleuze e Corpo e Cena e Máquina e... o ensaio "Imagem de um segredo: Deleuze, David Lynch a Pedagogia da percepção". Voltamos agora ao que não deixamos de amar. Trata-se de uma imagem precisa, a imagem de um sonho: em Twin Peaks, o sussurro de Laura Palmer (Sheryl Lee) ao ouvido do agente Dale Cooper (Kyle MacLachlan), revelando a verdade de sua história. Ele acabará aprendendo que a verdade não é mais que uma busca, e que a busca é a própria história. Na pedagogia lynchiana, a verdade é a imagem de um segredo, e é para esse segredo que agora retornamos.

Não alteramos em nada o texto, que se mantém tal como foi apresentado. Um ensaio de peças soltas, feito de inícios e seguidas interrupções. Gostamos de vê-lo como a imagem de um pensamento, mesmo que por vezes germinal, frágil e confuso. Em tempos de vidas isoladas, incorpóreas, um pequeno testemunho daquilo que nos faz sorrir e acreditar, ainda. 


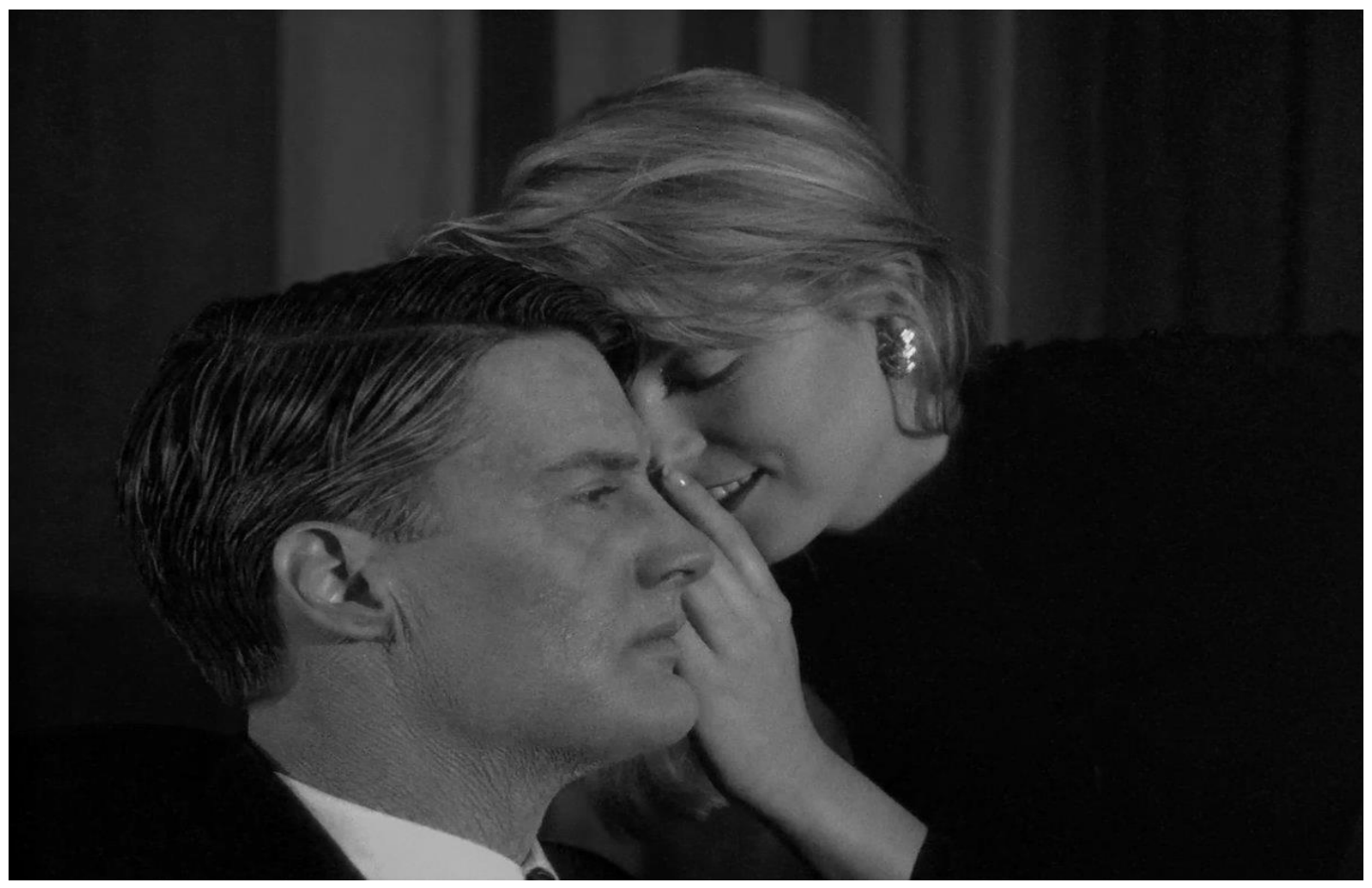

Frame de Twin Peaks (1991)

II.

Em entrevista concedida na ocasião da publicação de Cinema 1: A imagem-movimento, Deleuze (2016, p. 225), dizendo se considerar um espectador ingênuo, defende a ideia de que "todas as imagens de cinema são literais e portanto devem ser tomadas literalmente", em seu dado imediato. Destituída de qualquer profundidade, a imagem, tomada como imagem plana, não representa realidade alguma, sendo ela para si mesma toda a sua realidade, uma realidade à letra, em cheio, de chofre.

Estamos diante de uma estratégia de análise, de um artifício de pesquisa conhecido em Deleuze: ao invés da interpretação, da busca por um sentido oculto, ligado a uma realidade exterior, temos a experimentação, o pensamento a partir do dado sugerido pela imagem, que se torna assim tanto real quanto potencial: se pode haver algo a mais em uma imagem, esse excesso é o próprio movimento do pensamento que ela sugere. Nunca outra coisa. (Lembremos que dois anos antes da publicação dos livros sobre cinema, a pintura de Francis Bacon havia recebido tratamento semelhante. De uma imagem a outra, uma só questão: como escapar da representação? Como agenciar novas imagens de pensamento? Como perceber o novo, o ainda não pensado, não dito? Como, através da criação - seja ela filosófica, pictural ou cinematográfica - testemunhar e atestar uma existência até então apenas pressentida, uma existência que é apenas força, sensação?).

Para nós, trata-se de, em meio a tantas questões, articular uma outra: até que ponto esse modo "superficial" de enxergar e tomar a imagem enquanto matéria de pensamento, pode servir para o nosso trabalho de pesquisa e ensino, nos espaços que nos tocam? Dizendo de outro modo, o que podemos ver através de uma imagem de cinema, que não poderíamos ver e pensar sem ela, e que pode interessar à nossa prática educacional?

Sabemos que, para Deleuze, é a imagem que impõe ao espectador determinado uso dos olhos, dos ouvidos, do corpo. É a imagem que exige determinada postura para ser vista, e é sempre por meio de tais posturas, por meio da aprendizagem que elas envolvem (uma 
aprendizagem motora, cerebral, sensível), que se pode articular as ideias cinematográficas com aquelas advindas de outros campos de criação. Ou seja, a imagem vem sempre antes.

Obviamente, é preciso um corpo para entrar em uma arte por meio de outra. Precisa-se de um corpo para se fazer a passagem. No nosso caso, trata-se de um corpo docente que, por meio de um espaço-tempo imagético preciso, situa-se entre uma imagem e a educação, entre uma imagem e o espaço-tempo da aula. Mais especificamente, entre Deleuze, David Lynch e o que entendemos ser uma pedagogia da percepção. Para tanto, partimos de uma linha traçada por um gesto preciso: o sussurro de Laura Palmer ao ouvido de Dale Cooper.

Vamos a ela.

Entramos em Twin Peaks pelo corpo morto de Laura Palmer, para quem somos apresentados logo na primeira cena. Premissa clichê: garota mais popular da escola é assassinada em cidade do interior, oficial do FBI é designado para o caso, chega à cidade, a investigação tem início, a trama se desenvolve.

Nossa cena, que é a cena-leitmotiv de Twin Peaks, é a construção de um espaço tão preciso quanto escorregadio, um espaço delimitado apenas em sonhos, nas lembranças fabuladoras de tempo passado e nas potências do futuro. Ora, trata-se de um encontro impossível: quando ela se foi ele ainda não estava lá; ele só está lá porque ela se foi. Na materialidade do aqui e agora, um silencioso no man's land.

O que se passou?

De fato, entre é a discreta palavra que se desprende da cena e corre por toda a cidade. Não sabemos se o que vemos é passado ou futuro, não sabemos se estamos acordados ou sonhando. Estamos, sempre, entre dois mundos. Ao mesmo tempo, sabemos de Laura através dos movimentos de Cooper, aquele que vem depois e aponta para o que está por vir. Laura, a morta-viva.

É em um sonho que Laura sussurra para Cooper a verdade sobre seu assassinato, verdade essa que ele esquecerá, e do sonho manterá apenas aquilo que nos dá a ver em seu conteúdo manifesto. Assim como ele, sabemos que ela disse, mas jamais saberemos o que ela disse. Assim como ele, poderemos dizer: "Eu sei, mas não me lembro".

Em “1730 - Devir-intenso, devir-animal, devir-imperceptível”, Deleuze e Guattari (1997) defendem a ideia de que o segredo não é uma noção estática e imobilizada, mas sim um agenciamento coletivo. Seja como um conteúdo que se tornou grande demais para sua forma ou então como um conteúdo que tem nele mesmo uma forma vazia, como um continente apenas traçado e jamais preenchido, o segredo funciona como uma secreção: algo não localizável se passou, algo do que podemos apenas reter os efeitos.

Secreção: algo se passou com Laura = conteúdo revelado a Cooper. O segredo se torna então entre-dois, por onde algo passa = conteúdo molecularizado, a forma tornada linha, a linha traçando um continente vazio. Um bom segredo é um caso de devir...

Entre a boca de Laura Palmer e a orelha de Dale Cooper, partimos de uma linha de fuga, partimos da imagem de um segredo. Que se passou? O que poderá ter acontecido? O segredo permanecerá impenetrável, a imagem rasa - ou a imagem de superfície sem profundidade, segundo a terminologia de Serge Daney (2007) retomada por Deleuze -, a imagem rasa exige ser tomada literalmente, em sua planeza, apenas por aquilo que há nela e dentro dela: destacada do antes e do depois, uma imagem só vale pelos pensamentos que ela cria ou pelas novas funções de pensamento que ela desencadeia.

Para Deleuze, uma imagem cinematográfica (assim como uma imagem literária, pictural, musical ou literária) é um espaço particular, um meio no qual são produzidas imagens de pensamento a ele imanentes (ou seja, possíveis de serem pensadas apenas nesse meio). Nesse sentido, o exercício de pensar por imagens está diretamente relacionado a uma pedagogia da 
percepção, a uma pedagogia que insistentemente faz ver, ouvir e sentir de outros modos, pela força e sugestão imagéticas.

Um segredo jamais descoberto é uma realidade impenetrável, que impõe um movimento circular ao redor do informe, do que não está decidido, do que espanta e não deixa de nos fazer regressar ao sem-resposta. Entendendo que o ato de criação envolve um trabalho de pensamento, sendo que pensar é necessariamente ir de encontro à imagens-clichê e saberes estratificados, uma pedagogia da percepção coloca em cena um esforço que não é de descoberta e resolução de problemas, mas sim de repercussões e deslocamentos contínuos. Se o segredo não instaura uma profundidade, não há nada oculto e a história não irá avançar ou retroceder em favor de uma descoberta. O que o segredo encena é uma potencialidade inesgotável, uma força de suspensão que institui um avesso ao mesmo tempo em que escapa a toda possibilidade de revelação (talvez, um vacúolo de não-comunicação que escapa a todo controle, segundo os termos utilizados por Deleuze (1992) em "Controle e devir".

Secreto por transparência. Secreto por nada esconder. Secreto por ser raso. Secreto por não conter nada oculto, impenetrável como a porta cristalina. Secreto por um esquecimento fundamental, o agenciamento coletivo que envolve o segredo não é ligado à memória; encontrase e é justificado pela produção, não pela representação.

Para produzir, partir de uma linha de fuga, de uma imagem-clandestina que:

a. nos coloca em relação e nos faz evoluir na ambiência problemática do incognoscível (o segredo como matéria inapreensível, uma existência de borda que ultrapassa os limites da percepção);

b. nos oferece posturas (estados do corpo e do espírito diante do imperceptível que subjaz ao que está se passando ou acabou de acontecer);

c. instaura suspenses invertidos (que é esse nada presente que faz com que algo tenha acontecido?).

De Laura Palmer ao agente Dale Cooper, pelo acoplamento boca-orelha, pensa-se sempre entre-dois, tal como insistem Deleuze e Guattari. Partimos, portanto, do entre-lugar. Partimos de um sussurrado agenciamento coletivo e buscamos dar novas direções a linhas que já se encontram em movimento. Nesse espaço, o que está em jogo é a possibilidade ou não da existência de percepções e posturas outras, de alianças inéditas, de pactos marginais.

Clandestina, a imagem é uma máquina de guerra. Diante dela, a partir dela ou mesmo nela, pelos signos que emite e no espaço-tempo anônimo que engendra em sua pedagogia, podese, quem sabe, apreender a resistir, a suscitar acontecimentos e a compartilhar um mundo.

"Qual o ponto de vista daquele que se coloca, quando pode, entre as coisas? E quem, se for preciso, parte uma coisa em duas [a imagem ou a aula, por exemplo] para colocar-se entre elas?" (DANEY, 2007, p. 98).

Uma aula é uma montagem, e pode até mesmo dizer mais sobre o modo como realiza essa montagem do que sobre a matéria com a qual trabalha. Dimensão manual e humana de todo pensar, tal como nos ensina Godard em Imagem e palavra. Também a mão docente é aquela que aponta para o que está por vir, na medida em que plasma e organiza um mundo específico, um cenário de vida específico, que ela torna lúcido jogando em seu limite de inexistência. Tal como nos lembra Etienne Souriau (2017), é preciso toda uma arte para fazer ver, sentir e pensar aquilo que vimos, sentimos e pensamos; é preciso um verdadeiro combate para vencer uma sombra, para aprender e atestar o valor do que foi percebido, e então legitimar a realidade de sua existência.

O que se passa em uma aula? Para quais direções ela vai, a partir dos sentidos que ela ganha? Porque é certo que algo se passa: entre a boca e a orelha, entre o gesto e os olhos, entre um corpo e outro, há sempre um espaço de passagem, uma zona geralmente secreta, e por isso mesmo impenetrável. Talvez, não se trate tanto de buscar uma forma, seja ela de expressão ou 
de conteúdo. Talvez não se trate de avançar em busca de uma revelação, de uma verdade última que capaz de justificar o movimento empreendido. Talvez possamos ver, sem no entanto buscar nenhum sentido. Ou talvez possamos saber, mas ter esquecido. Digamos: não se trata de buscar uma forma para o pensamento, mas sim de torná-lo possível.

Talvez possamos dizer, à sombra deleuze-guattariana, que uma aula "tem tão pouco a ver com a memória do passado, ou com um ato de reflexão, que ela ocorre, ao contrário, a partir de um esquecimento fundamental" (DELEUZE; GUATTARI, 1996, p. 65).

Sequência: que se passou? - segredo - posturas, afetos e movimentos do corpo.

Para onde, agora?

O segredo é a arquitetura de um suspense invertido: não estamos na expectativa de algo que será revelado, mas sim sob o efeito de algo que se passou. Secreção e movimento. A imagem de um segredo instaura uma zona de jogo. Nela, o que vemos? Apenas o corpo e sua excursão. Aqui, é Roland Barthes (2004, p. 44), pelo modo particular como pensa os cruzamentos entre a fala e a escuta dentro de uma situação de ensino, e sobretudo ao idealizar a relação pedagógica como semelhante "às idas e vindas de uma criança que brinca em torno da mãe", que "dela se afasta e depois volta, para trazer-lhe uma pedrinha, um fiozinho de lã", e que assim vai desenhando "ao redor de um centro calmo toda uma área de jogo, no interior da qual a pedrinha ou a lã importam finalmente menos do que o dom cheio de zelo que deles se faz", nos ajuda a perspectivar a aula como uma zona necessariamente relacional, e a docência como a responsável primeira pela manutenção de tal dinâmica.

Idas e vindas. Coisinhas trazidas e levadas. Descobertas grandes ou minúsculas. Isso e depois aquilo. Entre os dois: o zelo, o cuidado, a repetição do gesto: sempre o que importa mais, sempre a proteção do que garante o movimento.

No limite, o que uma pedagogia da percepção nos ensina é justamente isso: para ver, para saber, talvez seja necessário, em algum ponto, esquecer.

"nós sabemos, mas...".

\section{Referências}

BARTHES, Roland. Aula. Trad. Leyla Perrone-Moisés. São Paulo: Cultrix, 2004

BARTHES, Roland. Fragmentos de um discurso amoroso. Trad. Márcia Valéria M. Aguiar. São Paulo: Martins Fontes, 2007.

DANEY, Serge. A rampa. Trad. Marcelo Rezende. São Paulo: Cosac Naify, 2007.

DELEUZE, Gilles. Conversações, 1972-1990. Trad. Peter Pál Pelbart. Rio de Janeiro: Editora 34, 1992.

DELEUZE, Gilles. Dois regimes de loucos: textos e entrevistas (1975-1995). Trad. Guilherme Ivo. São Paulo: Editora 34, 2016.

DELEUZE, Gilles. Cinema 2 - A imagem-tempo. Trad. Eloisa A. Ribeiro. São Paulo: Editora 34, 2018.

DELEUZE, Gilles; GUATTARI, Félix. Mil platôs - capitalismo e esquizofrenia, vol. 3. Trad. Aurélio G. Neto et al. Rio de Janeiro: Editora 34, 1996. 
DELEUZE, Gilles; GUATTARI, Félix. Mil platôs - capitalismo e esquizofrenia, vol. 4. Trad. Suely Rolnik. São Paulo: Editora 34, 1997.

DIDI-HUBERMAN, Georges. Cascas. Trad. André Telles. São Paulo: Editora 34, 2017.

FOSTER, Hal. O retorno do real: a vanguarda no final do século XX. Trad. Célia Euvaldo. São Paulo: Ubu Editora, 2017.

PARIS, Texas. Direção de Win Wenders. Twentieth Century Fox, 1984. 1 DVD (150 min.).

PRECIADO, Paul B. La conjuration des losers. Disponível em: https://www.liberation.fr/debats/2020/03/27/la-conjuration-des-losers_1783349. Acesso em: 28/04/2020.

SOURIAU, Étienne. Los diferentes modos de existencia. Ciudad Autónoma de Buenos Aires: Cactus, 2017.

TAKARA - A noite em que eu nadei. Direção de Damien Manivel e Igarashi Kohei. Zeta Filmes, 2017. 1 DVD (78 min.).

TWIN Peaks (Temporadas 1 e 2). Direção de David Lynch et al. Lynch/Frost Productions, 1990-1991. 10 DVDs (1501 min.).

TWIN Peaks - O retorno. Direção de David Lynch e Mark Frost. Nova Iorque: Showtime, 2017. 18 DVDs (1025 min.). 